\title{
Article
}

\section{Cone calorimetry studies of fire retardant soybean-oil-based copolymers containing silicon or boron: Comparison of additive and reactive approaches}

Sacristán, Marta, Hull, T Richard, Stec, Anna A, Ronda, Joan C., Galià, Marina and Cádiz, Virginia

Available at http://clok.uclan.ac.uk/1095/

Sacristán, Marta, Hull, T Richard ORCID: 0000-0002-7970-4208, Stec, Anna A, Ronda, Joan C., Galià, Marina and Cádiz, Virginia (2010) Cone calorimetry studies of fire retardant soybean-oil-based copolymers containing silicon or boron: Comparison of additive and reactive approaches. Polymer Degradation and Stability, 95 (7). pp. 1269-1274. ISSN 01413910

It is advisable to refer to the publisher's version if you intend to cite from the work. http://dx.doi.org/10.1016/j.polymdegradstab.2010.03.015

For more information about UCLan's research in this area go to http://www.uclan.ac.uk/researchgroups/ and search for < name of research Group>.

For information about Research generally at UCLan please go to http://www.uclan.ac.uk/research/

All outputs in CLoK are protected by Intellectual Property Rights law, including Copyright law. Copyright, IPR and Moral Rights for the works on this site are retained by the individual authors and/or other copyright owners. Terms and conditions for use of this material are defined in the policies page. 


\title{
Cone Calorimetry Studies of Fire Retardant Soybean-Oil-Based Copolymers Containing Silicon or Boron: comparison of additive and reactive approaches
}

Marta Sacristán ${ }^{1}$, T. Richard Hull ${ }^{* 2}$, Anna A. Stec ${ }^{2}$, Joan C. Ronda ${ }^{1}$, Marina Galià*1 ${ }^{*}$ Virginia Cádiz ${ }^{1}$

1 Departament de Química Analítica i Química Orgánica, Universitat Rovira i Virgili, Campus Sescelades, Marcel-lí Domingo s/n, 43007 Tarragona, Spain

${ }^{2}$ Centre for Fire and Hazard Sciences, University of Central Lancashire,

Preston, PR1 2HE, UK

${ }^{*}$ Corresponding author e-mail: marina.galia@urv.cat, TRHull@uclan.ac.uk

\begin{abstract}
The fire retardance and thermal stability of soybean-based copolymers reactively modified by copolymerization with trimethylsilylstyrene (SiST) and tris-(4-vinylphenylboroxine) (BST) have been compared with those prepared with equivalent amounts of the additive 1,3-diphenyl-1,1,3,3tetramethyldisiloxane (SiAD) and tris-(phenylboroxine) (BAD) and with the heteroatom free soybean based copolymers. The best results are obtained for the boron containing copolymers. The reactive or additive approach is a significant factor in terms of the level of fire retardance achieved.
\end{abstract}

\section{Introduction}

Biomaterials, chemicals, and energy from renewable resources have received considerable interest in recent years.[1] The advantages of using renewable feedstocks in polymer synthesis such as vegetable oils include their low cost, ready availability, and sustainability, as well as possibly enhanced 
compostability and biodegradability of the resultant polymer materials at their end of life.

Vegetable oils containing unsaturated fatty acids can be used in polymerizations to make biobased polymers.[2-5] However, in common with other aliphatic polymer materials they are highly combustible. The concept of sustainable development requires technologies to be developed which have minimum impact on health and the environment through the life cycle of the material; that is to say, its synthesis, fabrication, use, recycling and disposal. Since most synthetic materials cause disposal problems after use and unwanted fires cause major environmental damage, as well as wasting resources, it is essential that sustainable strategies for fire retardant materials are developed. The incorporation of silicon or boron functionality in the polymeric structure is recognized as one of the most efficient ways to obtain an environmentally friendly fire-retardant system.[6]

Generally, fire retardancy is achieved by the physical incorporation of additives; however, this method has several disadvantages.[7] For example, halogen based flame-retardant additives may be leached from the polymer to the environment, where they have been shown to act as endocrine disruptions. They also have to be used in significantly high concentrations in order to be effective, which may adversely affect the physical and mechanical properties of the material. The alternative strategy of using reactive flame retardants may be achieved by copolymerization with comonomers containing fire retardant groups. The relatively low loadings required to reduce the flammability do not produce significant changes in physical and mechanical properties of the polymer. Furthermore, the fire retardant chemical is then permanently attached to the polymer. This latter method is the focus of our study.

We have obtained fire retardant silicon-[8] or boron-containing[9] polymers by copolymerization of soybean oil and styrenic monomers containing covalently bonded silicon or boron. We have concentrated on the use of silicon and boron containing species as reactive modifiers as they have been investigated less than phosphorus species. Silicon compounds, when present in a polymer, have a fire retardant effect arising partly from vapour phase action, dilution of 
combustible organic gases in the flame zone, and partly from the formation of a barrier to heat and mass transfer that silicaceous residues can form behind the flame front.[10,11] Boron compounds thermally decompose producing boron oxide in the condensed phase and alter the decomposition process of the polymer in favour of carbonaceous residues rather than $\mathrm{CO}$ or $\mathrm{CO}_{2 .}[12,13]$ The aim of the present work is to explore the influence of these heteroatoms on the thermal and fire retardant properties of soybean oil-based copolymers, and to compare the combustion behaviour of silicon- or boron-containing polymers obtained by copolymerization with $\mathrm{Si}$ - or B-containing reactive fire retardants or by adding Si- or B-containing fire retardants additives (Scheme 1).

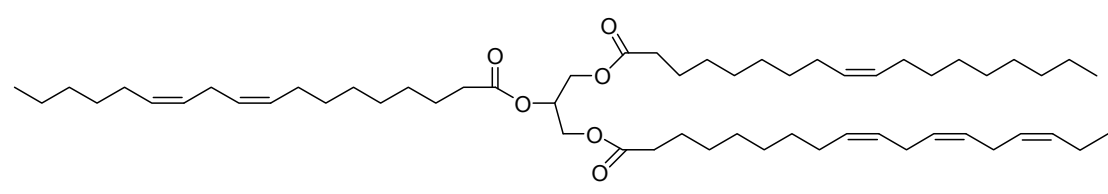

Soybean oil (SOY)

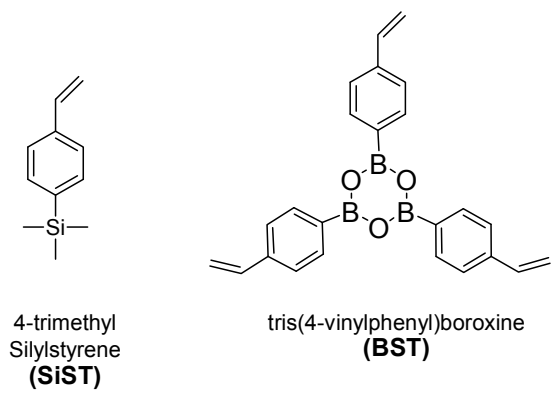

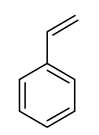

Styrene (ST)

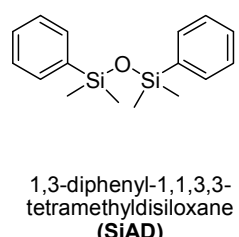

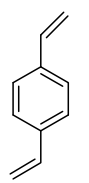

Divinylbenzene (DVB)

Scheme 1. Structures and identities of the additives and comonomers

Flammability is a complex scenario dependant phenomenon which cannot be represented by a single numerical quantity. Ignitability indicates proper sites for a fire to start, or for flame spread, and is often measured by easy of extinction tests such as the Limiting Oxygen Index (LOI, ISO 4589).[14] Cone calorimetry (ISO 5660)[15] gives a more complete picture of burning behaviour, particularly looking at spark piloted face ignition (using the retaining frame) with the sample in a horizontal orientation. Interpretation of cone calorimetry data for development of fire retarded materials has been discussed elsewhere.[16] 


\section{Experimental}

\subsection{Materials}

Soybean oil used in this study (iodine value = 135) was supplied by Aldrich Chemicals and has been used without further purification. Styrene (ST, 99.9\%) and divinylbenzene (DVB, 80\%) were purchased from Fluka and washed with a $\mathrm{NaOH} 10 \%$ solution and then with water. The distilled-grade boron trifluoride diethyl etherate $\left(\mathrm{BF}_{3} . \mathrm{OEt}_{2}\right)$ (Aldrich), methyl oleate (MeOL, 75\%) (Alfa Aesar), 1,3-diphenyl-1,1,3,3-tetramethyldisiloxane (SiAD) (ABCR) and tris(phenylboroxine) (BAD) (Aldrich) were used without further modification. 4trimethylsilylstyrene[8] and tris(4-vinylphenyl)boroxine[9] were obtained as previously described.

\subsection{Synthesis of polymer plaques}

The desired amounts of comonomers or additives were added to the soybean oil (Table 1). The reaction mixture was vigorously stirred, followed by the addition of an appropriate amount of a modified initiator (in a 3 mol\% of $\mathrm{BF}_{3} \mathrm{OEt}_{2}$ ratio to the total $\mathrm{C}=\mathrm{C}$ double bond in the polymerization mixture). The modified initiator was prepared by mixing $\mathrm{BF}_{3} \mathrm{OEt}_{2}$ and $\mathrm{MeOL}$ in a molar ratio 1.1:1.0. Plaques of the different copolymers for cone calorimetric experiments were prepared by mixing the different components. The mixtures were placed in a $100 \times 100 \times 2,0 \mathrm{~mm}^{3}$ aluminium moulds. Curing conditions are shown in Table1. 
Table 1. Molar ratio of the different copolymers synthesised (DVB:2.25, MeOL:0.36; $\mathrm{BF}_{3} \mathrm{OEt}_{2}: 0.41$ ) and curing conditions.

\begin{tabular}{|c|c|c|c|c|c|c|c|c|c|c|c|c|}
\hline \multicolumn{8}{|c|}{ Molar ratio } & \multicolumn{5}{|c|}{ Curing conditions } \\
\hline System & SOY & ST & SiST & SiAD & BST & BAD & $\% \mathrm{Si}$ & $\% \mathrm{~B}$ & $t(h)$ & $\mathrm{T}\left({ }^{\circ} \mathrm{C}\right)$ & $t(h)$ & $\mathrm{T}\left({ }^{\circ} \mathrm{C}\right)$ \\
\hline C & 1 & 6 & - & - & - & - & - & - & 12 & 60 & 24 & 110 \\
\hline CSiR & 1 & 2 & 4 & - & - & - & 5 & - & 12 & 60 & 24 & 140 \\
\hline CSiA & 1 & 6 & - & 2.3 & - & - & 5 & - & 12 & 90 & 24 & 160 \\
\hline CBR & 1 & 0 & - & - & 6 & - & - & 3 & 12 & 90 & 24 & 160 \\
\hline CBA & 1 & 6 & - & - & - & 8.1 & - & 3 & 12 & 120 & 24 & 160 \\
\hline
\end{tabular}




\subsection{LOI measurements (LOI ISO 4589)[14]}

These were performed on a Stanton Redcroft FTA flammability unit provided with an Oxygen Analyzer. Sample sizes measured $100 \times 5 \times 4 \mathrm{~mm}^{3}$ and were prepared by moulding.

\subsection{Thermogravimetric analysis (TGA)}

Dynamic thermogravimetric studies were used to investigate the behaviour in an oxidative and non-oxidative environment using a Mettler TGA/SDTA851e/LF/1100 instrument. For both air and nitrogen atmospheres a flow rate of $10 \mathrm{ml} / \mathrm{min}$ was used. Samples of $10-15 \mathrm{mg}$ were placed in open alumina pans and heated from 30 to $800{ }^{\circ} \mathrm{C}$ at a constant heating rate of 10 ${ }^{\circ} \mathrm{C} / \mathrm{min}$.

\subsection{Cone calorimetry}

The combustion behaviour of the polymer plaques, $100 \times 100 \times 2 \mathrm{~mm}$, was investigated using a Fire Testing Technology cone calorimeter in following ISO 5660[15], at a heat flux of $35 \mathrm{KW} \mathrm{m}^{-2}$, which is the recommended heat flux for exploratory testing.[17] The plaques were placed in the sample holder with a retainer frame, resulting in $88 \mathrm{~cm}^{2}$ of the sample surface being exposed to the radiation from the cone heater. Due to the processes involved in sample preparation each test was only carried out twice, giving an indication of the reproducibility of the results. Averages of the two values are presented in the results.

\subsection{Dynamic mechanical thermal analysis (DMTA)}

Mechanical properties were measured with a dynamic mechanical thermal analyzer (DMTA) (TA DMA 2928). Specimens $1.2 \mathrm{~mm}$ thick, $5 \mathrm{~mm}$ wide, and 10 $\mathrm{mm}$ long were tested in a three point bending configuration. The various thermal transitions were studied between -100 and $100^{\circ} \mathrm{C}$ at a heating rate of $3^{\circ} \mathrm{C} / \mathrm{min}$ and a fixed frequency of $1 \mathrm{~Hz}$. 


\section{Results and discussion}

\subsection{Combustion behaviour}

Soybean oil based copolymers containing silicon or boron covalently attached to the network and containing silicon or boron additives have been obtained with the compositions and curing conditions shown in Table 1.

The easy of extinction of these systems have been assessed by the LOI test and the results are given in Table 2. The LOI value of the heteroatom free soybean oil-based copolymer is 19.2 and increases significantly when silicon or boron, either in additive or reactive form, are added, indicating a reduction in ignitability. No significant differences are observed from the reactive and additive approach for a 3\% B content and only a small improvement is observed for a covalently bonded silicon containing copolymer (CSiR) compared to the silicon additive approach (CSiA).

Whilst measurement of LOI is a useful, small-scale test that correlates to the ignitability in polymers, it is not a reliable indicator of how a material will perform once ignited in a real fire. The most widely used method for this is the cone calorimeter, in which a polymer plaque is irradiated at a pre-determined heat flux, simulating the conditions of an advancing flame front. Some important parameters obtained for plaques of the different soybean-based copolymers prepared are given in Table 2. The difficulty in synthesizing large quantities of samples restricted the number of cone calorimeter tests to duplicates in each case. Averages are presented as to an appropriate number of significant figures. 
Table 2. LOI and cone calorimetric data measured with an irradiance of $35 \mathrm{~kW} / \mathrm{m}^{2}$.

\begin{tabular}{|c|c|c|c|c|c|c|c|}
\hline Samples & LOI & TTI (s) & $\begin{array}{l}\text { PHRR } \\
\left(\mathrm{kW} / \mathrm{m}^{2}\right)\end{array}$ & $\begin{array}{l}\text { THR } \\
\left(\mathrm{MJ} / \mathrm{m}^{2}\right)\end{array}$ & $\begin{array}{l}\text { FIGRA } \\
\left(\mathrm{KW} / \mathrm{m}^{2} \mathrm{~s}\right)\end{array}$ & $\begin{array}{l}\text { MARHE } \\
\left(\mathrm{KW} / \mathrm{m}^{2}\right)\end{array}$ & $\begin{array}{l}\text { Total smoke } \\
\text { release }\left(\mathrm{Kw} / \mathrm{m}^{2}\right)\end{array}$ \\
\hline$C$ & 19.2 & 25 & 510 & 36.7 & 7.3 & 235 & 740 \\
\hline CSiR & 28.6 & 37 & 620 & 43.8 & 8.8 & 244 & 1190 \\
\hline CSiA & 26.0 & 18 & 930 & 33.7 & 18.5 & 412 & 1400 \\
\hline CBR & 25.6 & 44 & 410 & 32.5 & 3.7 & 178 & 370 \\
\hline CBA & 25.2 & 52 & 530 & 32.8 & 6.6 & 278 & 990 \\
\hline
\end{tabular}


Ignition occurs when the mass loss rate produces sufficient volatiles with an effective heat of combustion capable of sustaining ignition piloted by a spark. The heteroatom containing samples have improved times to TTI, except for the CSiA system. While for the boron containing copolymers, the presence of the heteroelement seems to be a significant factor in the ignition time, for the silicon containing copolymers not only the presence of silicon but also the reactive nature of the fire retardant appears to be important. This could indicate an early decomposition of SiAD before it could play a role as a fire retardant.

The heat release rates (HRR) vs. time curves for the copolymers are presented in Figure 1. The HRR of $C$ increased rapidly after the initial $25 \mathrm{~s}$ and the peak heat release rate (PHRR) occurred at $70 \mathrm{~s}$ Subsequently, the HRR decreased rapidly until it became negligible after 300s. The shape of HRR curves is similar for all the copolymers. The results show a significant decrease of $20 \%$ on the value of PHRR for the CBR system, while the system with a similar boron content as a flame retardant additive show a value similar to the heteroatom free system. For the silicon containing copolymers, increases on the PHRR can be observed, especially important for the CSiA system. The values of the total heat evolved are very similar for all the samples. Unlike the time to ignition the heat release rate and the total heat evolved do not correspond to LOI results illustrating the difference of these parameters in fire retardancy studies.

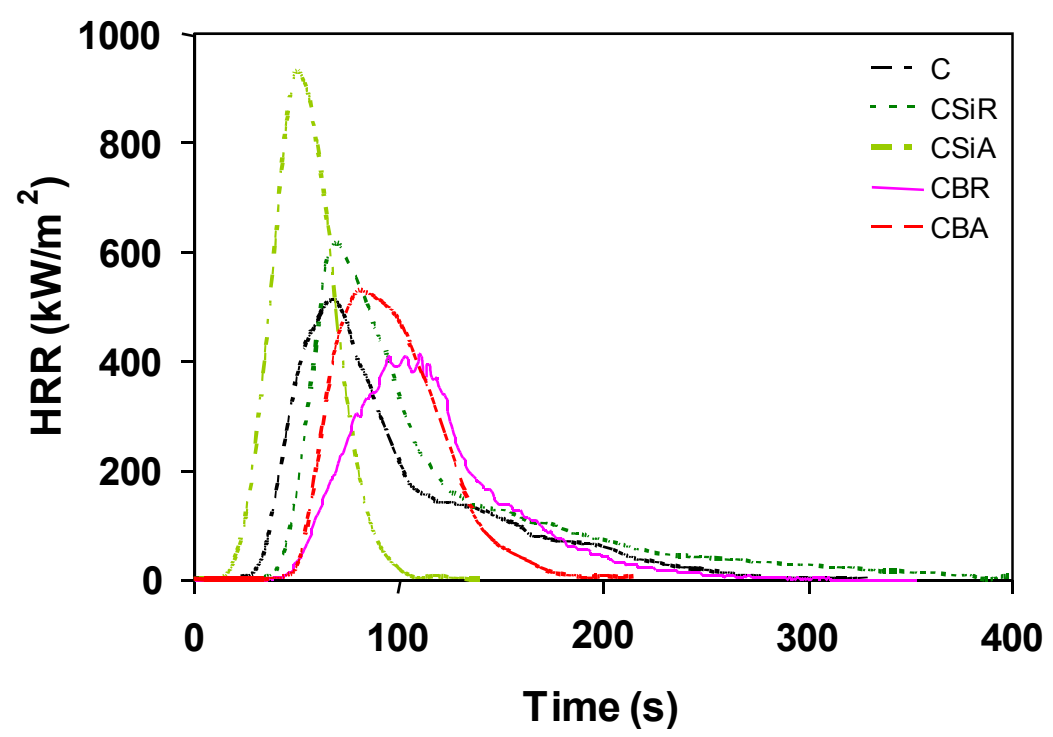

Figure 1. HRR vs. time for the different copolymers synthesised. 
The Fire growth rate index (FIGRA) is calculated by dividing the peak heat release rate by time to peak heat release rate, and can estimate both the predicted fire spread rate and the size of a fire. The FIGRA index clearly diminishes for the boron reactive flame retardant containing copolymer, giving comparable values for $\mathrm{CBA}$ and $\mathrm{CSiR}$ and a twofold value for CSiA.

The average rate of heat emission (ARHE) curve is reported in Figure 2. This parameter, defined as the cumulative heat emission divided by time and its peak value (Maximum average rate of heat emission, MARHE) can be considered a good measure of the propensity for fire development under real scale conditions. MARHE for CBR system shows a notable reduction (24\%) with respect to the $\mathrm{C}$ sample, while the incorporation of boron in additive form or silicon in reactive form show slight increases. The CSiA system, however, shows an increase of about $60 \%$.

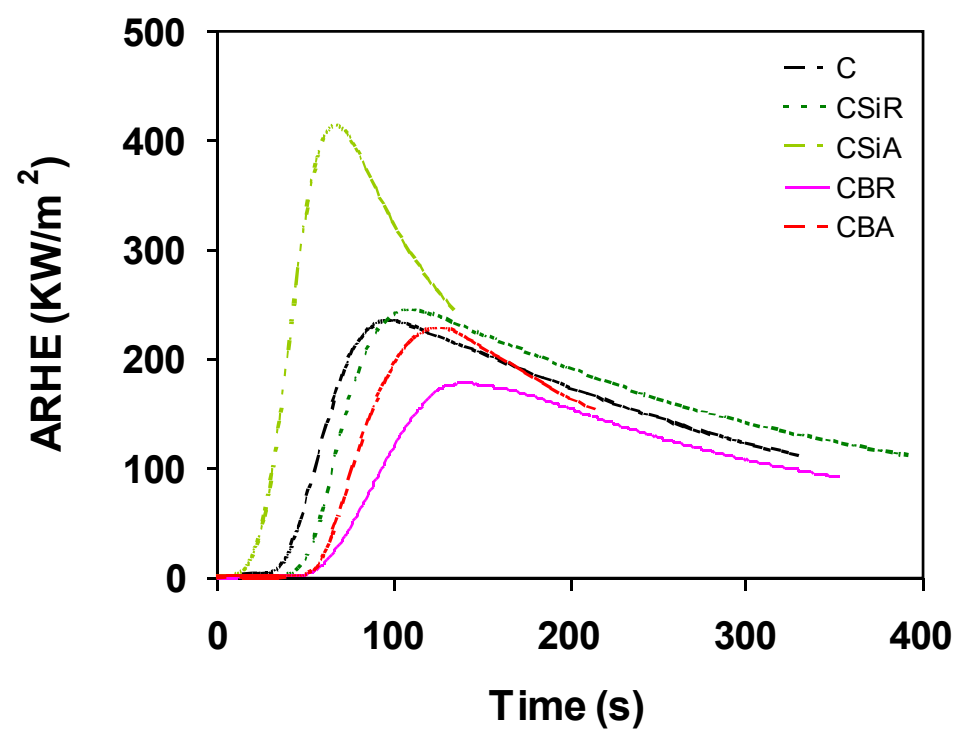

Figure 2. ARHE vs. Time for the different systems.

\subsection{Mass loss vs. time}

Percentage mass loss curves obtained as a function of time for the copolymer and additive systems are presented in Figure 3. The residual mass shown for the C, CSiR and CSiA systems is negligible. Conversely, the boron-containing copolymers (as reactive or additive fire retardants) showed a residual mass 
above $10 \%$ at the end of the tests. The observance of char seen during the cone calorimetry testing of CBR and CBA suggests a condensed-phase mechanism of fire retardancy. When these copolymers begin to burn and decompose, the boron oxide glass/boroxine networks, or organoceramic layers may act as a barrier to fuel transport and reradiate the incident flux from the cone calorimeter heater. Specifically, they are slowing the release of fuel from the decomposing polymer to the flame front. Furthermore, the char formation may occur through prevention of fuel flow to the flame front. Small molecules and decomposition products containing free radicals now have longer residence times in the condensed phase and, as such, are more likely to form char.[18-22] The values of the residual mass after combustion in cone calorimetry correlate well with the improvement in the peak heat release rate determined by cone calorimetry, according to a fire retardant mechanism being related to the formation of a char layer, except for CBA.

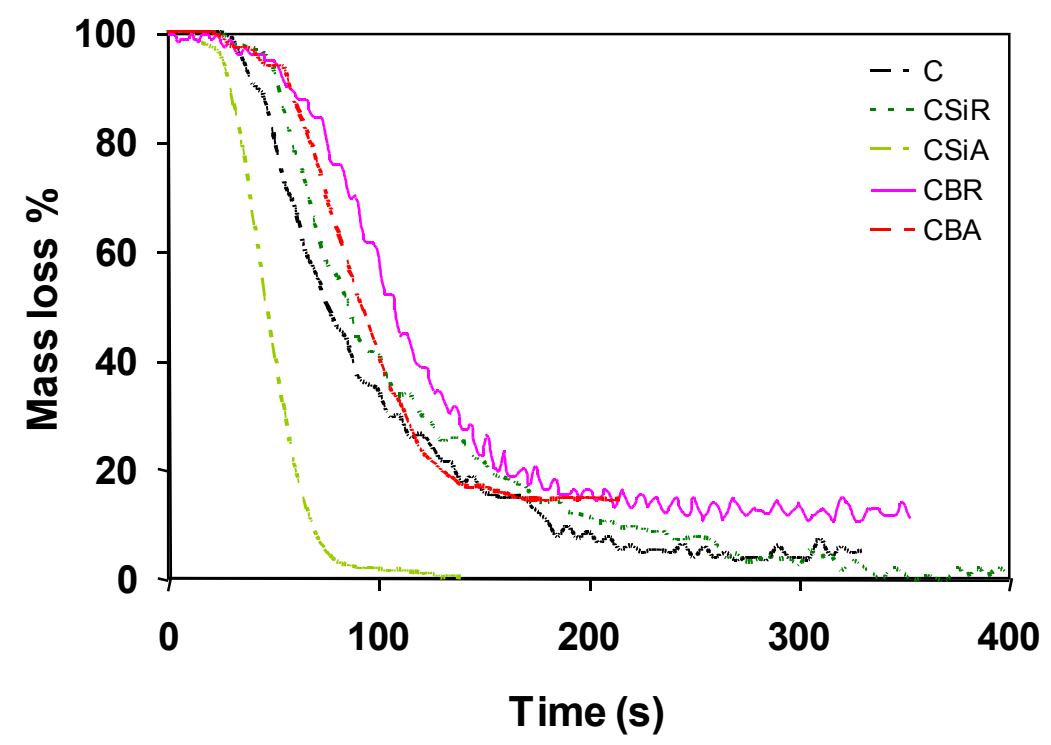

Figure 3. Mass loss curves (\%) vs. Time for the different samples.

The thermal stability and decomposition behaviour of the copolymers were investigated by thermogravimetric analysis (TGA). Figure 4 presents the TGA curves of the copolymers in air and in $\mathrm{N}_{2}$, and the thermogravimetric data are given in Table 3. When comparing char yields in nitrogen and air atmospheres obtained by TGA with the residual masses after combustion in cone calorimetry a good correlation can be observed, showing a close relationship between the 
cone calorimeter and TGA char yields in nitrogen atmosphere that highlights the anaerobic environment under a flame during combustion and the role of char formation in improving fire performance.[23]
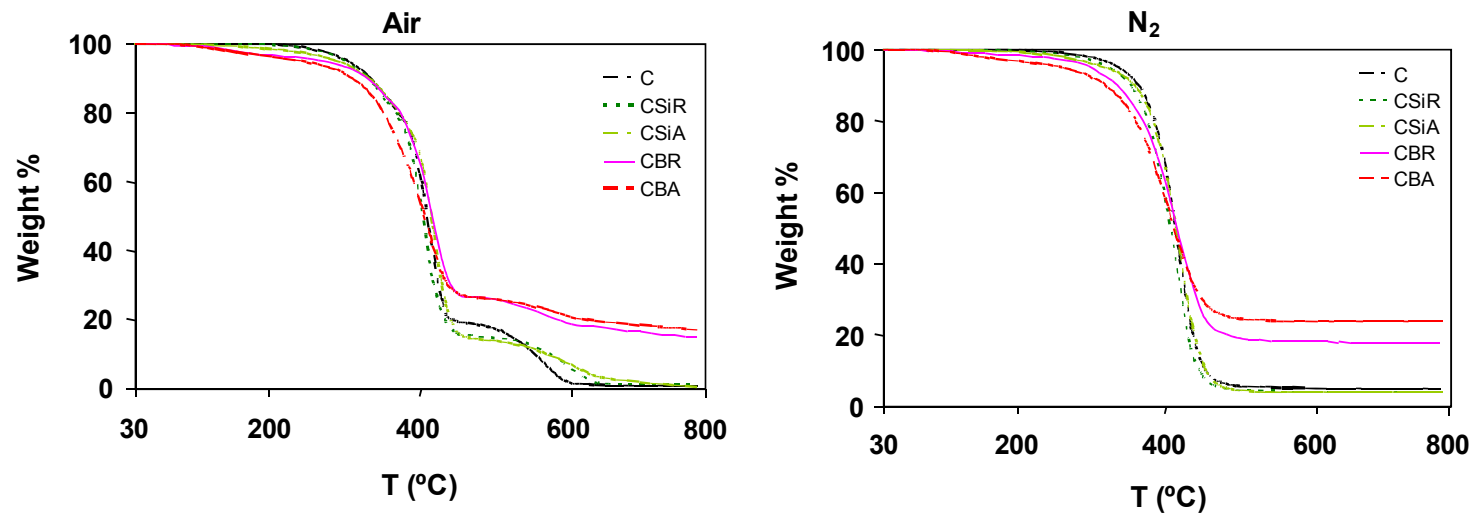

Figure 4. TGA curves of the different systems in air and $\mathrm{N}_{2}$

As can be seen, the presence of silicon covalently bonded to the polymer does not significantly change the thermal stability of the material. The polymer containing reactive boron fire retardant shows much lower thermal stability. For CBA, the weight loss at low temperatures has been attributed to the dehydration reaction of boronic acid groups that can be formed by partial opening of the boroxine rings after the curing process. The temperatures at which the additive containing polymers begin to degrade are lower than the corresponding reactive fire retardant containing polymers, a consequence of the volatilisation of SiAD and BAD. No differences can be observed on the shape of the reactive and additive-containing polymers for each heteroatom, according to the degradation behaviour previously described for these copolymers.[8,9] 
Table 3. Residue from cone calorimeter and termogravimetric tests.

\begin{tabular}{|c|c|c|c|c|c|}
\hline \multirow[t]{2}{*}{ Samples } & \multirow[t]{2}{*}{ Cone calorimeter (\%) } & \multicolumn{2}{|c|}{ TGA Nitrogen } & \multicolumn{2}{|c|}{ TGA Air } \\
\hline & & $\mathbf{T}_{5 \%}{ }^{\mathrm{a}}\left({ }^{\circ} \mathrm{C}\right)$ & Char ${ }^{\underline{b}}(\%)$ & $\mathrm{T}_{5 \%}{ }^{\mathrm{a}}\left({ }^{\circ} \mathrm{C}\right)$ & Char ${ }^{\text {b }}(\%)$ \\
\hline C & 4.0 & 349 & 4.7 & 317 & 0.6 \\
\hline CSiR & 0.7 & 340 & 3.8 & 310 & 0.9 \\
\hline CSiA & 0.2 & 330 & 3.5 & 301 & 0 \\
\hline CBR & 10.9 & 311 & 15.9 & 290 & 13.7 \\
\hline CBA & 14.4 & 269 & 23.3 & 251 & 16.6 \\
\hline
\end{tabular}


The shape of the weight loss curves obtained from the cone calorimeter test are similar to those obtained from thermogravimetry in nitrogen, but show differences with those obtained from thermogravimetry in air. On heating in a thermobalance at $10^{\circ} \mathrm{C} / \mathrm{min}$ in air, our systems show a two-step weight loss corresponding to two different degradation mechanisms (decomposition of soluble polymer fractions and degradation of the crosslinked network)[8,9] whereas a single step is observed during the combustion test. This can be due to the different heating conditions during the cone calorimeter test where a high heating rate and a high temperature are reached.

\section{3 Smoke and $\mathrm{CO}$ evolution}

Due to the presence of aromatic structures, burning these systems evolves large amounts of smoke that is known to be hazardous in fire situations. Only the sample containing the reactive boron fire retardant shows a significant decrease in the amount of smoke evolved, thus showing that the incorporation of boron covalently bonded to the copolymer reduces the smoke hazard compared to the soybean oil copolymer. The amounts of smoke evolved in our cone experiments were consistently higher for the samples containing additive fire retardants than reactive fire retardants.

The temporal behaviour of $\mathrm{CO}$ evolution rate during the cone calorimetry experiments is shown in Figure 5. As can be seen, the fire-retardant strategy applied, i.e. additive vs. reactive approach, did not significantly influence the amounts of $\mathrm{CO}$ evolved during combustion which generally follows the heat release curve. Both $\mathrm{CO}$ and smoke production indicate the fire retardancy mechanism. Flame inhibition results in an increase in combustion products typical for incomplete combustion, with corresponding increases in $\mathrm{CO}$ and smoke production whereas increased charring shows no change or even a reduction in the absolute $\mathrm{CO}$ production due to an unchanged yield (based on mass lost and a reduced total mass loss). The boron containing samples evolved less $\mathrm{CO}$ and at a slower rate than the soybean oil copolymer, according to a condensed phase fire retardant mechanism. The silicon containing samples evolved more $\mathrm{CO}$ at a faster rate than the heteroatom free copolymer. This 
could indicate that the presence of silicon as a reactive or additive fire retardant has a more important effect in the vapour phase.[24]

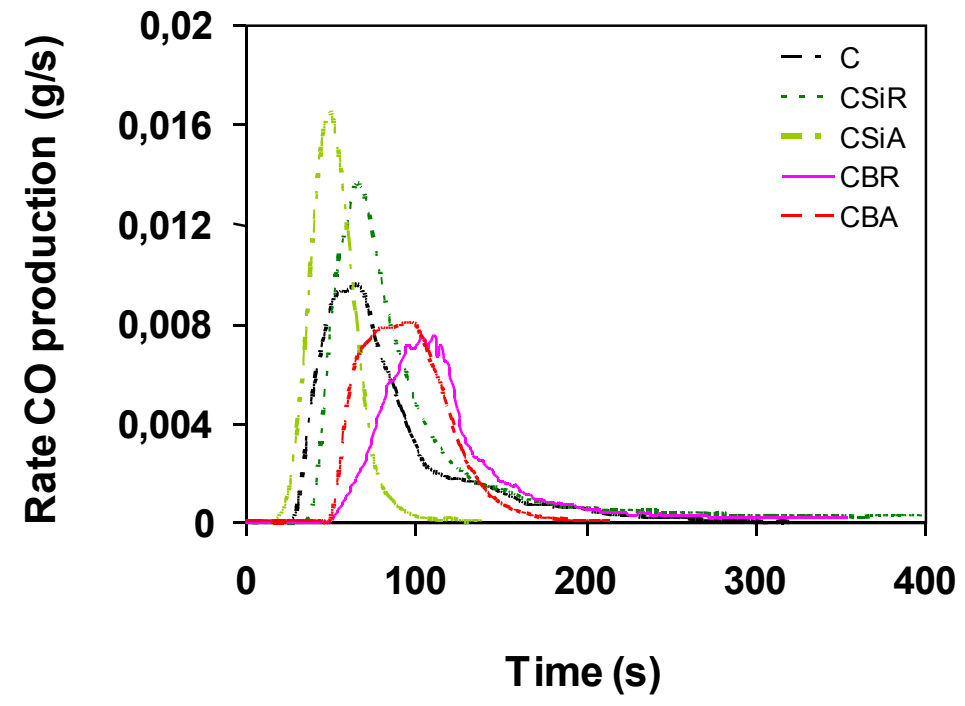

Figure 5. CO evolution vs. time for copolymers.

\subsection{Dynamic mechanical thermal analysis (DMTA)}

The DMTA data (Figure 6) obtained showed that chemical bonding of the silicon and boron moiety to the polymer backbone had a small effect on the $T_{g}$ value. The copolymers appear to be composed of hard aromatic rich phases and soft oil rich phases with a certain amount of oligomers and unreacted monomers that act as plasticisers, thus causing a shift of the $T_{g}$ to lower temperatures. On the other hand, the physical incorporation of silicon and boron additives into the polymer system resulted in a significant reduction in the mechanical properties of the system. As can be seen, the incorporation of high amounts of additives into the polymer has an important plasticising effect that causes a broadening of the Tan $\delta$. 


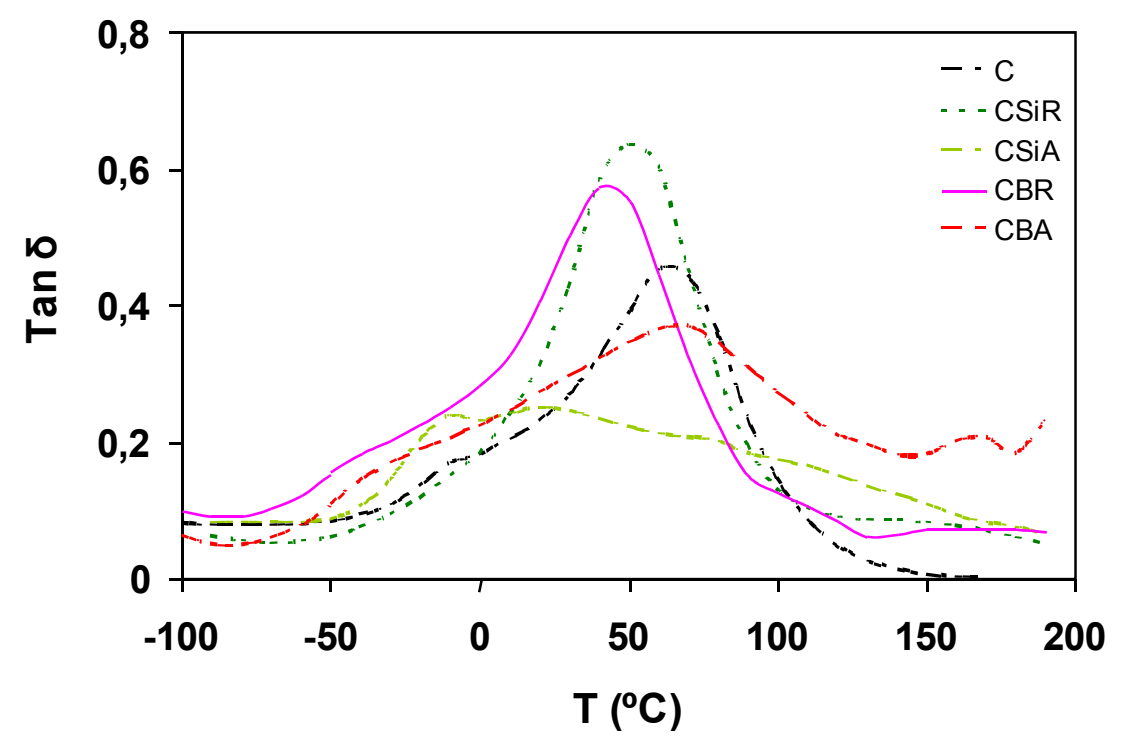

Figure 6. Tan $\delta$ of copolymers as function of temperature.

\section{Conclusions}

The development of new materials from renewable sources is essential if current levels of consumption are to be supported in a sustainable manner. In order to avoid compromising fire safety, it is necessary to develop fire retardant strategies for these new materials. Since most fire retardant formulations are polymer specific, it is necessary to investigate both the burning and decomposition behaviour of such new systems, in order to develop materials meeting current specifications. The incorporation of reactive fire retardant monomers containing boron and silicon has shown potential in these novel polymer systems.

Limiting oxygen index tests give useful information about the ignitability of the material, while cone calorimetry gives information on both the ignitability, and the burning behaviour. The cone calorimetry experiments gave much clearer evidence than the LOI measurements that incorporation of $\mathrm{Si}$ or $\mathrm{B}$ into the soybean oil copolymer resulted in fire retardation. This indicates the formation of a protective layer following ignition, reducing the rate of gas-phase fuel formation. The boron-containing copolymers were found to be more efficient flame retardants for this system than were the silicon-containing copolymers. Moreover, the reactive or additive approach is a significant factor in terms of the level of fire retardance achieved and significant improvements are obtained 
when reactive flame retardants are used. This may result from improved dispersion of the reactive fire retardant moieties compared to the corresponding additives, or their presence in the polymer chain may promote crosslinking and char formation.

\section{References}

[1] Bozell JJ, Patel M, eds. Feedstocks for the Future: Renewables For the Production of Chemicals and Materials. ACS Symposium Series 921. Washington, DC: American Chemical Society 2006.

[2] Lu Y, Larock RC. Novel polymeric materials from vegetable oils and vinyl monomers: Preparation, properties and applications. ChemSusChem 2009, 2:136-147.

[3] Belgacem MN, Gandini A, eds. Monomers, Polymers and Composites from Renewable resources. Oxford: Elsevier 2008.

[4] Meier MAR, Metzger JO, Schubert US. Plant oil renewable resources as green alternatives in polymer science. Chem Soc Rev 2007; 36: 1788-1802.

[5] Güner FS, Yagci Y, Erciyes AT. Polymers from triglyceride Oils. Prog Polym Sci 2006, 31: 633-670.

[6] Lu SY, Hamerton I. Recent developments in the chemistry of halogen-free flame retardant polymers Prog. Polym Sci 2002, 27:1661-1712.

[7] Cullis CF, Hirschler MM. The Combustion of Organic Polymers. Clarendon Press, Oxford 1981.

[8] Sacristán M, Ronda JC, Galià M, Cádiz V. Silicon-containing soybean-oilbased copolymers. Synthesis and properties. Biomacromolecules 2009, 10:2678-2685.

[9] Sacristán M, Ronda JC, Galià M, Cádiz V. Effects on the flame retardancy of boron-containing soybean-oil based copolymers. Polym Deg Stab Submitted [10] Kashiwagi T, Gilman JW. In: Grand AF, Wilkie CA, eds. Fire retardancy of polymeric materials. Marcel Dekker Inc., New York 2000.

[11] Ebdon JR, Hunt BJ, Jones, MS, Thorpe FG. Chemical modification of polymers to improve flame retardance II. The influence of silicon containing groups. Polym Deg Stab 1996, 54:395-400. 
[12] Hilado CJ, ed. Flammability Handbook for Plastics, $2^{\text {nd }}$ Technomic Publications (Lancaster, PA) 1974.

[13] Armitage P, Ebdon JR, Hunt BJ, Jones MS, Thorpe FG. Chemical modification of polymers to improve flame retardance.l. The influence of boroncontaining groups. Polym Degrad Stab 1996, 54:387-393.

[14] ISO 4589-2:1996 Plastics - Determination of burning behaviour by oxygen index - Part 2: Ambient-temperature test, Geneva. ISO 56601990 Fire testsreaction to fire- rate of heat release from building products.

[15] ISO 56601990 Fire tests- reaction to fire- rate of heat release from building products.

[16] Schartel B, Hull TR, Development of fire-retarded materials-Interpretation of cone calorimeter data, Fire and Materials 2007, 31:327-354.

[17] Recommendations for the use of the cone calorimeter, STD.BSI DD 246ENGL; 1999.

[18] Martin DC, Spilman GE, Markoski LJ, Jiang T, Pingel E. Flame resistance of benzocyclobutene (BCB) functionalized copolymers, Soc Plast Eng Tech Papers 1996, 42:3008.

[19] Butler KM, Baum HR, Kashiwagi T. Three-dimensional modeling of intumescent materials, Soc Plast Eng Tech Papers 1996, 42, 3063.

[20] Factor, A. in Fire and Polymers; ACS Symposium-Series 425. American Chemical Society, Washington, DC 1990; p 274.

[21] Van Krevelen DW. Some basic aspects of flame resistance of polymeric materials. Polymer 1975, 16:615-620.

[22] Morgan AB, Jurs JL, Tour JM. Synthesis, flame-retardancy testing and preliminary mechanism studies of nonhalogenated aromatic boronic acids: A new class of condensed-phase polymer flame retardant additives for acrylonitrile-butadiene-styrene and polycarbonate. J Appl Polym Sci 2000, $76: 1257-1268$

[23] Lyon, RE. Heat release kinetics. Fire Mater 2000, 24 :179-186.

[24] Price D, Bullett KJ, Cunliffe, LK, Hull TR, Milnes GJ, Ebdon, JR, Hunt, BJ, Joseph P. Cone calorimetry studies of polymer systems flame retarded by chemically bonded phosphorus. Polym Deg Stab 2005, 88 :74-79. 